\title{
Screening of Antibiotype among Environmental Isolates of Acinetobacter spp. in Hospital Setting
}

\author{
Kritu Panta ${ }^{1}$, Prakash Ghimire ${ }^{1}$, Shiba K. Rai ${ }^{2}$, Reena K. Mukhiya², \\ Ram N. Singh ${ }^{3}$ and Ganesh Rai ${ }^{3}$ \\ ${ }^{1}$ Central Department of Microbiology, Tribhuvan University \\ Kirtipur, Kathmandu \\ ${ }^{2}$ Shi-Gan Health Foudation, Nat'l Institute of Tropical Medicine and Public Health Research \\ Kathmandu \\ ${ }^{3}$ Nepal Police Hospital \\ Maharjgunj, Kathmandu \\ e-mail: itskritu@gmail.com
}

\begin{abstract}
Cross infection through hospital environment has been a major challenge to control nosocomial infection. This has been worse with the emergence of multidrug resistant strains. The present study was conducted to study the pattern of antibiotic resistant group of Acinetobacter spp. in hospital environment to understand possibility of nosocomial infection. The study was conducted for a period of six months during which Acinetobacter spp. from 269 samples of hospital environment (air sample, surface swab and hand swab from healthcare workers) were identified by conventional microbiological method and antibiogram was performed by Kirby-Bauer disc diffusion method and NCCLS guidelines. Bacterial isolates obtained from both samples were tested for their relatedness based on their resistivity pattern among the tested antibiotics. Of the total environmental samples 212 samples were found to be positive and a total of 183 gram negative isolates were obtained. Of the total gram negative isolates, 84.2\% (154/183) Acinetobacter spp. were isolated. Analysis of MDR isolates revealed 70.8\% (109/154) Acinetobacter spp. which was MDR. A total of 12 different antibiogram patterns were found with five different antibiotic groups tested.
\end{abstract}

Key Words antibiogram typing, antibiogram type, environment, MDR, nosocomial

\section{Introduction}

Acinetobacters are normal environmental dwellers that have a extremely rapid propensity to develop antibiotic resistance (Katsutoshi et al. 2003, Stéphane et al. 2003). They can be found on a range of dry or moist inanimate surfaces and as commensals on the skin of man and animal (Forbes et al. 2007, Peleg et al. 2008). These have also been recognized as an important pathogens involved in outbreaks of hospital acquired infection (Buisson et al. 1990, Guillou 1991) particularly in high- dependency cases or ICUs (Sague et al. 1990). In developed countries many surveys and control programs are implemented so as to prevent transmission of pathogens from hospital environment to the patients (Orsi et al. 2005, Wilks et al. 2006, Zolldan et al. 2005). On the other hand, in the context of resource poor countries like Nepal, there are less studies carried out to identify the Acinetobacter spp. as potential pathogen for nosocomial infection.

\section{Methodology}

This study was carried out at 100 bed hospital in Kathmandu. A total of 134 surface swab samples from different locations were taken. Surface swabs was taken from bed fabric, bed bar, equipment rack, wash basin, scissors, etc using sterile cotton swabs soaked in brain heart infusion broth (BHI). About a total of 81 hand swabs were taken, the entire area of palm and between fingers was rubbed with sterile swab, dipped in BHI broth. Air samples were collected by plate exposure technique.

The swab samples were inoculated in NA plates and MacConkey plates and incubated at $37^{\circ} \mathrm{C}$ for $24 \mathrm{hrs}$. 
Identification of isolates done based on the morphological and biochemical characters. Antibiotic susceptibility testing was done to the isolates identified as Acinetobacter spp. by Kirby-Bauer disc diffusion method. Ampicillin (10 mcg/disc), Cotrimoxazole (25mcg/disc), Gentamycin (10 mcg /disc), Ciprofloxacin (5 mcg /disc), Ceftazidime (30 mcg/disc), Ceftriazone (30mcg/ disc) and Amoxicillin (10mcg/disc) were used.

\section{Results and Discussion}

Of the total 134 swab samples from different inanimate objects close to patient; 103 samples was found to be positive and Acinetobacter spp. was found in 77 positive samples. Similarly of total 54 plate exposure sample 43 was found to be positive and Acinetobacter spp. was found from 41 different sites. Similarly of the total 81 hand swabs taken from health care workers, 47 swab sample showed positive growth of which in the
36 sample Acinetobacter spp. was isolated, the illustration of the Acinetobacter isolated from the sample is shown in Fig. 1.

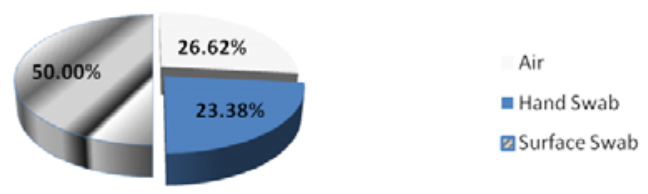

Fig. 1. Occurrence of Acinetobacter spp. in Different Samples

Table 2 showed the antibiotic resistivity pattern of the isolated Acinetobacter spp. Quinolones (Ciprofloxacin) was the most effective followed by cotrimoxazole and gentamycin while the other aminoglycoside, amikacin was found to be least sensitive.

\begin{tabular}{l|lll} 
Table 1. Resistivity Pattern of the isolates \\
\hline Group number & Antibiotics Group & Antibiotic & Resistance n(\%) \\
Group 1 & Aminopenicillins & Ampicillin & $97(62.98 \%)$ \\
& & Amoxicillin & $88(57.17 \%)$ \\
Group 2 & Sulphonomides & Co-trim oxazole & $34(22.08 \%)$ \\
Group 3 & Quinolones & Ciprofloxacin & $15(9.74 \%)$ \\
Group 4 & Aminoglycosides & Gentam ycin & $35(22.72 \%)$ \\
& & Amikacin & $100(64.93 \%)$ \\
Group 5 & Cephalosporins & Cefotaxime & $73(47.40 \%)$ \\
& & Ceftriaxone & $65(42.21 \%)$ \\
\hline
\end{tabular}

Each isolates were grouped into different antibiotypic group based on their resistivity pattern. Grouping of antibiotics was done as stated in Table 1. Different antibiotype group is indicated in Roman Numerals.
The 12 different antibiotype groups were found. Analysis of the MDR (resistant to two or more than two groups of antibiotics) showed that $70.8 \%$ of the isolated Acinetobacter spp.

Table 2. Antibiotyping of the isolates

\begin{tabular}{l|l|c|c}
\hline \multicolumn{1}{c|}{ Antibiotype } & Description (Resistant group) & II umber & Percent (\%) \\
\hline I & All sensitive & 17 & 11.04 \\
II & Group 1 & 25 & 16.23 \\
III & Group 4 & 1 & 0.65 \\
IV & Group (1+4) & 14 & 9.09 \\
V & Group 5 & 1 & 0.65 \\
VI & Group (5+1) & 6 & 3.89 \\
VII & Group (5+2+1) & 3 & 1.95 \\
VIII & Group (5+ 4) & 3 & 1.95 \\
IX & Group (5+ 4+1) & 35 & 22.73 \\
X & Group(5+4+2+1) & 29 & 18.83 \\
XI & Group (1+3+4+5) & 8 & 5.19 \\
XII & All resistant & 12 & 7.79 \\
\hline Total & & 154 & \\
\hline
\end{tabular}


Acinetobacter spp. has become an increasing problem in health-care-associated infections over the past few years (Bernards et al. 2004, Fournier \& Richert 2006, Maragaskis et al. 2008, Seifert \& Dowzicky 2009).The Nation Nosocomial Infection Study (NNIS) reported a 6.9\% increase in Acinetobacter spp. causing hospitalacquired pneumonias in ICUs in 2003,up from $1.4 \%$ in 1975 (Gaynes \& Edward 2005). In addition, this organism has the ability to persist and colonize environmental surfaces for prolonged periods of time and biofilm formation, thereby contribute to its pathogenicity, increased transmission rates and association with nosocomial outbreaks (Kunz and Brook 2010, Dallo \& Weito 2010).

From several studies it has been shown isolates of Acinetobacter spp. particularly A. baumannii, those recovered from patients with nosocomial infections, are frequently resistant to multiple antimicrobial agents, including cephalosporins, aminoglycosides, and quinolones (Fournier \& Richert 2006, Gaynes \& Edward 2005). The report of environmental analysis of occurrence of Acinetobacter spp. in hospital environment of Nepal is rarely available while the study of susceptibility pattern of the genus from different clinical samples has been done in different hospitals. In a research done in Eighty-six strains of Acinetobacter spp. particularly A. baumanii from India and Nepal for the presence of integrons in relation to multiple drug resistance by integrase gene polymerase chain reaction (PCR), integrons were found to be present at a rate of $43.02 \%$ (37/86) and integrons were significantly correlated with multidrug resistance to several antibiotics (Gaur et al. 2007). Out of 195 bacterial isolates obtained from surgical wound infection in Nepal, 13 bacterial species were identified and Acinetobacter spp. ranked 5th with the prevalence rate of 7.6\%, and 9 strains were MDR (Banjara et al. 2003). In this study, all A. baumannii isolates were multidrug resistant. All were resistant to beta-lactam antibiotics tested. Some isolates were resistant to all antibiotics tested while others were sensitive to aminoglycosides and fluoroquinolones. Strains resistant to these antibiotics and to carbapenems have already been reported elsewhere (Chaiwarith et al. 2005, Thapa et al. 2010). Similarly occurrence of oligonal A. baumanii has been reported from study on nosocomial infection in Nepal (Thapa et al. 2011). In the current study also, though the analysis up to molecular basis was not performed but the antibiotyping reveled the existence of 104 MDR strains which was more than $50 \%$ of the total isolates, this showed high occurrence of Acinetobacter spp. capable of causing nosocomial infection.

From the study done in BPKIHS, Dharan similar type of result of AST pattern was observed; as in this study gentamicin was found to be most effective than cephalosporins and amikacin and also ciprofloxacin was found to be effective than $3^{\text {rd }}$ generation cephalosporins (Ghimire et al. 2007). In another research it was found that $50.0 \%$ of Acinetobacter spp. was resistant to the imipenem (Tiwari et al. 2007). However this differs with the research done in Taiwan where ampicillin was found to be most effective drug than cephalosporins and quinolones while in this study this has been found as one of the least effective drug among tested (Hsueh et al. 2002) his difference may be particularly due to difference in hospital settings and use of the antibiotics.

Acinetobacter spp. is often transferred from the hands and nostrils of health workers of hospital personnel to patients and result in significant morbidity, especially in intensive care and rehabilitation units (Ramazanzadeh 2009, Nicasia et al. 2008, Perez et al. 2007). It was demonstrated that the hands of medical staff and the surface area can be an important source during nosocomial outbreaks (NNIS 2004, Paterson 2008, Perez et al. 2007). In our research though the transmission has not yet been established but the isolation of Acinetobacter spp. from hand swab shows the possibility of accidental transmission.

Acinetobacter spp. have been isolated from various types of opportunistic infections, including septicemia, pneumonia, endocarditis, meningitis, skin and wound infection, and urinary tract infection (Mittal et al. 2003, Prashanth \& Badrinath 2005). The occurrence of Acinetobacter spp. in hospital air has been related to one of the significant cause of ventilator associated pneumonia (Husni et al. 1999). Though in this research no such clinical data of occurrence of complications due to Acinetobacter spp. has been recorded but since the bacteria is abundantly present in hospital environment, chances of cross-infection is inevitable.

The true frequency of nosocomial infection caused by Acinetobacter spp. is not easy to assess, partly 
Nepal Journal of Science and Technology Vol. 13, No. 2 (2012) 203-208

because the isolation of these organisms from clinical specimens may not necessarily reflect infection but, rather, may result from colonization (Bergogne \& Towner 1996). The result obtained from this research therefore cannot be confirmed for the occurrence for the nosocomial infection in the hospital but however maximum occurrence of Acinetobacter spp. and their varying antibiotype focus over the need of cleaning, disinfection and sterilization of hospital environment.

The prevention of nosocomial infection demands a thorough knowledge of the infection rates and of the source, type and nature of invading microorganisms along with the risk factors associated with infection (Weinstein 1991). Among the most popular bacteria causing nosocomial infection Acinetobacter spp. has emerged as a new challenge to health care workers; the so-called 'super bug' (A. baumanni) (CDC 1996). Thus this study focused on the MDR Acinetobacter spp. that may cause the health care crisis.

\section{Acknowledgements}

We thank Dr. Dwij Raj Bhatta, Ms Jyotsna Shrestha, Mr Dev Raj Joshi and entire staff of Nepal Police Hospital, Shi-Gan Health foundation and Central Department of Microbiology for support in successful completion of this research work.

\section{References}

Banjara, M.R., A.P. Sharma, A.B. Joshi, N.R. Tuladhar, P. Ghimire and D.R. Bhatta. 2003. Surgical wound infections in patients of Tribhuvan University Teaching Hospital. Nepal Health Res Counc. 1(2): 41-45.

Beck-Sague, C.M., W. R. Jarvis, J.H. Brook, D.H. Culver, A. Potts, E . Gay, B.W. Shotts, B. Hill, B.L. Anderson and M.P. Weinstein. 1990. Epidemic bacteremia due to Acinetobacter baumannii in five intensive care units. Am. J. Epidemiol. 132(4):723-733.

Bergogne, E. and K.J. Towner. 1996. Acinetobacter spp. as Nosocomial Pathogens: Microbiological, Clinical, and Epidemiological Features. Clin Microbiol Rev.9 (2):148-165.

Bergogne-Berezin, E. and M.L. Joly-Guillou. 1991. Hospital infection with Acinetobacter spp.: An increasing problem. J. Hosp. Infect. 18 (Suppl. A):250-255.

Bernards, A.T., H.I. Harinck, L. Dijkshoorn, T.J. Reijden and P.J. Broek. 2004. Persistent Acientobacter baumannii? Look inside your medical equipment. Infect Control Hosp. Epidemiol. 25(11):1002-1004.
Buisson, Y, L. Nhieu, P. Ginot, H. Bouvet, L. Schill and M. Meyran. 1990. Nosocomial outbreaks due to amikacinresistant tobramycin-sensitive Acinetobacter species: correlation with amikacin usage. J.Hosp. Infect. 15(1):83-93.

CDC, Hospital Infections Program: National Nosocomial Infections Surveillance (NNIS) Report. 1996. Data summary from October 1986-April 1996. Am. J. Infect. Control. 24(5):380-388.

Chaiwarith, R., S. Mahattanaphak, M. Boonchoo, K. Supparatpinyo and K. Sirisanthana. 2005. Pandrugresistant Acinetobacter baumannii at Maharaj Nakorn Chaingmai Hospital. J. Infect. Dis. Antimicrob. Agent . 22(1):1-8.

Dallo, S.F. and T. Weitao . 2010. Insights into acinetobacter war-wound infections, biofilms, and control. Adv. Skin Wound Care 23(4):169-174.

Forbes, A.B., F.D. Sahm and S.A. Weissfelt . 2007. Bailey and Scott's diagnostic Microbiology 12th edition. Mosby publication. 216-533pp

Fournie,r P.E. and H. Richert. 2006. The epidemiolog and control of Acientobacter baumannii in health care facilities. Clin. Infect. Dis. 42(5):692-699.

Gaur, A., P. Prakash, S. Anupurba and T.M. Mohapatra. 2007. Possible role of integrase gene polymerase chain reaction as an epidemiological marker: study of multidrug-resistant Acinetobacter baumannii isolated from nosocomial infections. Int. J. Antimicrob. Agents 29(4):446-450. Epub Jan 31.

Gaynes, R. and J.R. Edwards. 2005. National nosocomial infections surveillance system: Overview of nosocomial infections caused by gram-negative bacilli. Clin. Infect. Dis. 41(6):848- 854.

Ghimire, G., J.K.G Magar, S. Bhattacharya and T.M. Mahapatra . 2005. Acinetobacter spp.: A major isolates of nosocomial infection's - Clinical significance and antimicrobial susceptibility. Journal of Institute of Medicine 27(2):20-23.

Hsueh, P.R., L.J. Teng, C.Y. Chen, W.H. Chen, C.J.Yu, S.W. Ho and K.T. Luh . 2002. Pandrug-resistant Acinetobacter baumannii causing nosocomial infections in a university hospital, Taiwan. Emerg. Infect. Dis. 8(8):827-832.

Husni, R.N., L.S. Goldstein , A.C. Arroliga , G.S. Hall , C. Fatica, J.K. Stoller and S.M. 1999. Risk factors for an outbreak of multi-drug-resistant Acinetobacter nosocomial pneumonia among intubated patients. Chest 115(5):13781382

Katsutoshi, Y., K. Masaru , Y. Tomonari, S. Koichi, U. Toshiro, N. Hisaaki, S. Kaori, W. Ryoudou, K. Shohiro and A. Masanori. 2003. Production of CTX-M-3 extendedspectrum â-lactamase and IMP-1 metallo â-lactamase by five Gram-negative bacilli: survey ofclinical isolates from seven laboratories collected in 1998 and 2000, in the Kinki region of Japan. Japanese Antimicrobial Chemotherapy 51(3):631-638. 
Kunz, A.N. and I. Brook . 2009. Emerging resistant gramnegative aerobic bacilli in hospital-acquired infections. Chemother. 56(6):492-500.

Maragaskis, L.L., and Perl T.M. 2008. Acientobacter baumannii: epidemiology, antimicrobial resistance, and treatment options. Clin. Infect. Dis. 46(8):1254-1263.

Mittal, N., D. Nair, N. Gupta, D. Rawat, S. Kabra and S. Kumar. 2003. Outbreak of Acinetobacter spp. septicemia in a neonatal ICU. Southeast Asian J. Trop. Med. Public Health 34(2):365-366.

National Nosocomial Infections Surveillance System: National Nosocomial Infections Surveillance (NNIS) System Report. 2004. Data summary from January 1992 through issued June 2004 October 2004. Am. J. Infect. Control 32(8):470-485.

Nicasia, A.M., D.P. Nicolau and J.L. Kuti 2008. The current state of multidrug-resistant gram-negative bacilli in North America. Pharmacotherapy 28(2):235-249.

Orsi, G.B., M. Raponi, C. Franchi, M. Rocco, C. Mancini and M. Venditti. 2005. Surveillance and inection control in an intensive care unit. Infect. Control Hosp. Epidemiol. 26(3): 321-325.

Paterson, D.L. 2004. 'Collateral damage' from cephalosporin or quinolone antibiotic therapy. Clin. Infect. Dis. 38(suppl 4):S341-S345.

Peleg, A.Y., S. Harald and D.L. Paterson. 2008. Acinetobacter baumannii: Emergence of a successful pathogen. Clinical Microbiological Reviews 21(3):538-582.

Perez, F., A.M. Hujer, K.M. Hujer , B.K. Decker, P.N. Rather and R.A. Bonomo. 2007. Global challenges of multidrugresistant Acinetobacter baumannii. Antimicrob Agents Chemother. 51(10):3471-3484.

Prashanth, K. and S. Badrinath. 2005. Epidemiological investigation of nosocomial Acinetobacter infections using arbitrarily primed PCR \& pulse field gel electrophoresis. Indian J. Med. Res. 122(5):408-418.

Ramazanzadeh, R., M. Chitsaz and N. Bahmani. 2009. Prevalence and antimicrobial susceptibility of extended- spectrum beta-lactamase-producing bacteria in intensive care units of Sanandaj general hospitals (Kurdistan, Iran). Chemotherapy 55(4):287-292.

Seifert, H and M.J. Dowzicky. 2009. A longitudinal analysis of antimicrobial susceptibility in clinical institutions in Germany as part of the Tigecycline Evaluation and Surveillance Trial (2004-2007). Chemotherapy 55(4):241-252

Stephen, P, Denyer, A. Norman, Hodges and P. Sean. 2004. Pharmaceutical Microbiology. Blackwell Publishing 7:117-233.

Thapa, B, T.C. Chanwit and S.M. Basnet. 2011. Emergence of oligoclonal Acinetobacter baumannii nosocomial infection in a hospital in Nepal. African Journal of Microbial Research 5(32):5872-5876.

Thapa, B.C. Tribuddharat, S. Srifuengfung and C. Dhiraputra. 2010. High prevalence of blaOXA-23 in oligoclonal carbapenem resistant Acinetobacter baumannii from Siriraj Hospital, Madhidol University, Bangkok, Thailand. South East Asian J. Trop. Med. 41(3):625-635.

Tiwari, K.B., B. Rijal, P.Ghimire and A.P. Sharma. 2007. Acute bacterial meningitis in Nepal. Nepal Medical College Journal 9(2):100-103.

Weinstein, R.A. 1991. Epidemiology and control of nosocomial infections in adult intensive care units. Am. J. Med. 91(Suppl. 3B):179S-184S.

Wilks, M., A. Wilson, S. Warwick, E. Price, D. Kennedy, A. Ely and M.R. Millar. 2006. Control of an outbreak of multidrug-resistant Acinetobacter baumanniicalcoaceticus colonization and infection in an intensive care unit (ICU) without closing the ICU or placing patients in isolation. Infect. Control Hosp. Epidemiol. 27(7):654-658.

Zolldann, D., C. Spitzer, H. Häfner, B. Waitschies, W. Klein, D. Sohr, F. Block, R. Lütticken and S.W. Lemmen. 2005. Surveillance of nosocomial infections in a neurological intensive care unit. Infect. Control Hosp. Epidemiol. 26(8):726-731. 
Nepal Journal of Science and Technology Vol. 13, No. 2 (2012) 203-208 